\title{
Soil salinity increases the tolerance of excessive sulfur fumigation stress in tomato plants
}

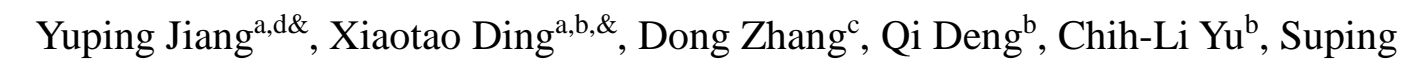
Zhou $^{\text {d }}$, Dafeng Hui ${ }^{\text {b* }}$

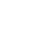

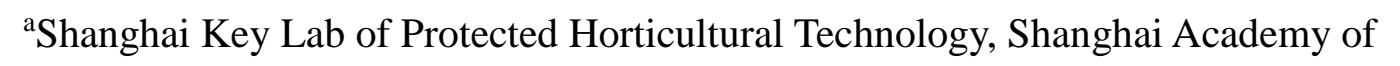
Agricultural Sciences, Shanghai 201106, China.

${ }^{\mathrm{b}}$ Department of Biological Sciences, Tennessee State University, Nashville, Tennessee 37209, United States of America.

${ }^{c}$ Xuzhou Institute of Agricultural Sciences, Jiangsu Academy of Agricultural Sciences, Xuzhou 221121, China.

${ }^{\mathrm{d}}$ Department of Agricultural and Environmental Sciences, Tennessee State University, Nashville, Tennessee 37209, United States of America.

\& Yuping Jiang and Xiaotao Ding contributed equally to this work.

*Correspondence should be addressed to D. Hui (email: dhui@tnstate.edu), Tel.: +1 615 9635777; fax: +1 6159635783.

Abbreviations: Car, carotenoid; Chl, chlorophyll; $C_{i}$, intercellular $\mathrm{CO}_{2}$ concentration; DW, dry weight per unit area; ETR, electron transport rate; $F_{m}$, maximal fluorescence yields in dark-adapted state; $F_{m}$ ', maximal fluorescence yields in 
light-adapted state; $\mathrm{F}_{0}$, minimal fluorescence yields in dark-adapted state; $\mathrm{F}_{0}$ ', minimal fluorescence yields in light-adapted state; Fs, steady-state fluorescence yields in light-adapted state; Fv/Fm, maximum quantum efficiency of PSII photochemistry; Fv'/Fm', effective quantum yield of PSII photochemistry; FW, fresh weight per unit area; $G_{s}$, stomatal conductance; $P_{n}$, net photosynthetic rate; PSII, photosystem II; QA, primary quinone electron acceptor of PSII; qN, non-photochemical quenching coefficients; qP, photochemical quenching coefficient; $T_{r}$, transpiration; $\Phi_{\mathrm{PSII}}$, actual photochemical efficiency of PSII.

\section{ABSTRACT}

To investigate the responses of plant photosynthesis and chlorophyll fluorescence to excessive sulfur fumigation stress (Sulfur) alleviated by pre-treated salt in the soil (Salt), seedlings of a tomato cultivar (Solanum lycopersicum L. 'Money Maker') were exposed to the Sulfur with or without the Salt treatment for 15 hours. Leaf fresh weight, dry weight, chlorophyll (Chl) content, carotenoid (Car) content, photosynthesis and chlorophyll fluorescence parameters were measured. The results showed that the Sulfur treatment significantly decreased leaf fresh weight, dry weight, $\mathrm{Chl}$ and Car contents, net photosynthetic rate $\left(P_{n}\right)$, stomatal conductance $\left(G_{s}\right)$, transpiration rate $\left(T_{r}\right)$, maximum quantum efficiency of photosystem II (PSII) photochemistry $\left(\mathrm{F}_{\mathrm{v}} / \mathrm{F}_{\mathrm{m}}\right)$, actual photochemical efficiency of PSII ( $\left.\Phi_{\mathrm{PSII}}\right)$, photochemical quenching coefficient $(\mathrm{qP})$, electron transport rate (ETR), and the effective quantum yield of PSII photochemistry $\left(\mathrm{F}_{\mathrm{v}}{ }^{\prime} / \mathrm{F}_{\mathrm{m}}{ }^{\prime}\right)$. In addition, the Sulfur 
treatment significantly increased intercellular $\mathrm{CO}_{2}$ concentration $\left(C_{i}\right)$ and non-photochemical quenching coefficients (qN). Plants in soil pre-treated with salt clearly experienced less damage from sulfur toxicity, and these plants were able to retain higher leaf mass per area, greater total $\mathrm{Chl}$ and Car contents and photosynthetic activities, and to maintain the integrity of their chlorophyll fluorescence systems than fumigated plants growing in soil that was not pre-treated.

Reduced leaf photosynthesis in the Sulfur treatment was due to non-stomatal limitation, and to disturbance of the chlorophyll fluorescence system which needs more energy consumption for thermal dissipation. Our results showed that a cross-tolerance exists between the salt stress and extreme sulfur fumigation stress, and plants pre-treated with salt provided some protection against excessive sulfur toxicity.

Keywords: Sulfur fumigation stress; Salt stress; Cross-tolerance; Tomato; Chlorophyll fluorescence

\section{Introduction}

Plants are often subjected to various abiotic and biotic stresses, such as extreme temperatures, drought, salinity, microbial infection, herbicides, and exposure to other chemicals throughout their life cycles (Wang et al., 2015). To survive under these adverse conditions, plants have evolved many adaptive physiological and biochemical mechanisms to increase their tolerance to both primary and induced secondary stresses (Ma et al., 2013). Soil salinity is an important environmental 
problem worldwide. It limits plants seed germination, seedling growth, vegetative growth, flowering, fruit set, and decreases crop yields (Munns and Tester, 2008). Most of the numerous studies of salt stress found that it is harmful to plant growth and development (Yi et al., 2015; Serna et al., 2015; Türkan and Demiral, 2009).

Sulfur is an essential macronutrient for all living organisms and is essential for proper plant growth and development (Lewandowska and Sirko, 2008; Astolfi et al., 2012; Celletti et al., 2016). Astolfi and Zuchi (2013) found that plant sulfur status plays a key role in coping with salt stress. Lee et al. (2016) demonstrated that sulfur use efficiency was positively correlated with high tolerance to drought stress. Sulfur is also used as pesticide to kill tomato-potato psyllid (Bactericera cockerelli) (Wright et al., 2015), and as fungicide to control cucumber powdery mildew (Podosphaera xanthii) (Cerkauskas and Ferguson, 2014) in vegetable production systems. Rao and Paria (2013) reported that sulfur nanoparticles can be used as a green pesticide on Fusarium solani and Venturia inaequalis. Sulfur is used as a safe organic pesticide (USEPA, 1991). Sulfur fumigation (application using a heated container to evaporate sulfur as a vapor) is often used in protected greenhouse vegetable cultivation. It is an important, traditional, and highly efficient method that kills microbes, fungi, and insects (Jiang et al., 2013). However, excessive sulfur fumigation may suppress plant growth or even have lethal effects (Dodd and Doley, 1998; Cerkauskas and Brown, 2015).

Cross-tolerance is a phenomenon in which a plant that is tolerant to one stress also is tolerant to another stress (Capiati et al., 2006; Zhou et al., 2014). Previous 
studies have indicated that cross-tolerance is essential for plant survival under multiple stresses. For instance, increased chilling tolerance is reported in maize plants that grew under drought conditions (Aroca et al., 2003). Cross-tolerance has also been reported for $\mathrm{NaCl}$ and heat-shock induced resistance to UV-B in barley, and for salt and drought tolerance in mustard seedlings (Carkirlar et al., 2008;

Puniran-Hartley et al., 2014; Hossain et al., 2013). But it is not clear if there is a cross-tolerance between excessive sulfur fumigation stress and salt stress in tomato plants.

In this study, tomato plants were pre-treated with salt for 14 days in a greenhouse and then exposed to excessive sulfur fumigation to investigate plant responses and test whether pre-exposure to salt would make the tomato plants more tolerant to excessive sulfur fumigation stress. We hypothesized that 1) both excessive sulfur fumigation and salt stresses would significantly reduce leaf photosynthesis and leaf growth; and 2) plants in the sulfur fumigation and salt stress treatment would perform better than in the sulfur fumigation only treatment, as plants pre-treated with salt could protect the plant leaves by promoting leave metabolite accumulation, and maintaining the activities of leaf photosynthetic system. Plant leaf properties and chlorophyll fluorescence parameters were measured to evaluate the potential for cross-tolerance between excessive sulfur and salt stresses. This information will help us to understand the changes in photosynthetic and chlorophyll fluorescence systems under both excessive sulfur fumigation and salt stresses and could be useful for management of agricultural production system. 


\section{Materials and methods}

\subsection{Plant material and treatments}

The tomato (Solanum lycopersicum L. cv) 'Money Maker' seeds were sown in peat-vermiculite mixture $(2: 1, \mathrm{v} / \mathrm{v})$ in a heated greenhouse. The temperature in the greenhouse was maintained at $25{ }^{\circ} \mathrm{C}$ during the day and $18{ }^{\circ} \mathrm{C}$ at night. No supplemental light was provided. After the third true leaf was fully expanded, plants were transplanted into five gallon pots. Each pot was filled with $20 \mathrm{~kg}$ of $0.09 \%$ total nitrogen, $0.05 \%$ available phosphate, and $0.07 \%$ soluble potash. There were 3 seedlings in each pot and 20 pots were used in this study. Plants were watered with Hoagland nutrient solution.

When the ninth true leaves began to expand, salt pre-treatment was started. Ten burned a total of $21.5 \mathrm{~g}$ of sulfur. The greenhouse was $14.7 \mathrm{~m} * 7.5 \mathrm{~m} * 4 \mathrm{~m}$, and the 
133

134

volume was about $331 \mathrm{~m}^{3}$, so the quantity of sulfur fumigation was about $4.33 \mathrm{mg}$ $\mathrm{m}^{-3} \mathrm{~h}^{-1}$. The greenhouse was closed and fans circulated air while the sulfur was burning.

The experiment used a completely randomized design with four treatments and five replicates (pots) of each treatment. Two greenhouses were used. Four treatments included: (1) CK: plants grown in greenhouse one, with no salt pre-treatment and no excessive sulfur fumigation stress applied; (2) Salt: plants grown in greenhouse one, pre-treated with $100 \mathrm{mM}$ of $\mathrm{NaCl}$ and no excessive sulfur fumigation stress applied;

(3) Sulfur: plants grown in greenhouse two, not pre-treated with salt, but fumigated with excessive sulfur; and (4) Salt+Sulfur: plants grown in greenhouse two, both pre-treated with $100 \mathrm{mM}$ of $\mathrm{NaCl}$ and fumigated with excessive sulfur.

\subsection{Leaf gas exchange and chlorophyll fluorescence analysis}

Leaf gas exchange and chlorophyll fluorescence were measured at 10:30 AM one day after the sulfur treatment. The largest leaves of each treatment at the same heights were measured and then harvested after the gas exchange and fluorescence measurements in order to measure leaf mass per area and chlorophyll content.

Leaf gas exchange and chlorophyll fluorescence were measured using a Li-6400 Portable Photosynthesis System (Li-Cor Inc., Lincoln, NE, USA) on fully developed leaves from the middle of each plant. Irradiance level was set at $600 \mu \mathrm{mol}$ photons $\mathrm{m}^{-2} \mathrm{~s}^{-1}$. Air temperature, air relative humidity, and $\mathrm{CO}_{2}$ concentration were set at ambient conditions in the greenhouse. The net photosynthetic rate $\left(P_{n}\right)$, stomatal conductance $\left(G_{s}\right)$, intercellular $\mathrm{CO}_{2}$ concentration $\left(C_{i}\right)$ and transpiration rate 
155

156

157

158

159

160

161

162

163

164

165

166

167

$\left(T_{r}\right)$ of tomato leaves were analyzed. Chlorophyll fluorescence was measured on the same leaves as those used for the gas exchange measurements. Chlorophyll fluorescence in dark- and light-adapted leaves was excited, and measured. Minimal $\left(\mathrm{F}_{0}\right)$, maximal $\left(\mathrm{F}_{\mathrm{m}}\right)$ fluorescence yields and maximum quantum efficiency of photosystem II (PSII) photochemistry $\left(\mathrm{F}_{\mathrm{v}} / \mathrm{F}_{\mathrm{m}}\right)$ was determined after a 30 min dark acclimation of selected leaves using a dark leaf clip, and $\mathrm{F}_{\mathrm{v}} / \mathrm{F}_{\mathrm{m}}$ was calculated as $\left(F_{m}-F_{0}\right) / F_{m}$ (Kitajima and Butler, 1975). For steady-state fluorescence yield (Fs) in light-adapted leaves, an actinic light source $\left(600 \mu \mathrm{mol}\right.$ photons $\left.\mathrm{m}^{-2} \mathrm{~s}^{-1}\right)$ was applied to achieve steady state photosynthesis, after which a second saturation pulse was applied for $0.7 \mathrm{~s}$ to obtain maximum fluorescence $\left(\mathrm{F}_{\mathrm{m}}{ }^{\prime}\right)$. The minimal fluorescence level in light-adapted state $\left(\mathrm{F}_{0}{ }^{\prime}\right)$ was determined by illuminating the leaf for $3 \mathrm{~s}$ with a far-red light. The actual photochemical efficiency of PSII ( $\Phi_{\text {PSIII }}$, and photochemical quenching coefficient $(\mathrm{qP})$ were calculated as $\mathrm{qP}=\left(\mathrm{F}_{\mathrm{m}}{ }^{\prime}-\mathrm{F}_{\mathrm{s}}\right) / \mathrm{F}_{\mathrm{m}}$, $\left(F_{\mathrm{m}}{ }^{\prime}-\mathrm{F}_{\mathrm{s}}\right) /\left(\mathrm{F}_{\mathrm{m}}{ }^{\prime}-\mathrm{F}_{0}{ }^{\prime}\right)$, following $\mathrm{Lu}$ et al. (2003). Electron transport rate was calculated as ETR $=\left(\mathrm{F}_{\mathrm{m}},-\mathrm{F}_{\mathrm{s}}\right) / \mathrm{F}_{\mathrm{m}}, * \mathrm{PPFD} * 0.5 * 0.84$, where PPFD is photosynthetic photon flux density incident on the leaf, 0.5 as the factor that assumes equal distribution of energy between the two photosystems, and 0.84 as the factor for leaf absorbance (Krall and Edwards, 1992). Effective quantum yield of PSII photochemistry was calculated as $\left(\mathrm{F}_{\mathrm{v}}{ }^{\prime} / \mathrm{F}_{\mathrm{m}}{ }^{\prime}\right)=\left(\mathrm{F}_{\mathrm{m}}{ }^{\prime}-\mathrm{F}_{0}{ }^{\prime}\right) / \mathrm{F}_{\mathrm{m}}{ }^{\prime}($ Rohacek, 2002). Using the fluorescence data obtained with the same dark-adapted and steady-state-illuminated leaves, non-photochemical quenching coefficients ( $\mathrm{qN}$ ) was calculated as $\mathrm{qN}=1$ $\left(F_{m}{ }^{\prime}-F_{o}{ }^{\prime}\right) /\left(F_{m}-F_{o}\right)$. Measurements of photosynthesis and fluorescence parameters 
177

178

were repeated once for each leaf, and at least five leaves from different pots were measured per treatment.

\subsection{Leaf fresh weight and dry weight measurements}

After the leaves were sampled for gas exchange and fluorescence measurement, samples were taken using a hole puncher. Samples were weighted for fresh weight, and then dried in an oven at $80^{\circ} \mathrm{C}$ for 5 days and reweighted for dry weight. At least five replicates per pot were analyzed in each treatment.

\subsection{Measurements of chlorophyll content, and Carotenoid content}

Leaf tissues $(0.5 \mathrm{~g})$ were ground in $80 \% \mathrm{v} / \mathrm{v}$ acetone. After centrifugation, the supernatant was used to measure absorbance at 663,645 and $470 \mathrm{~nm}$ using a UV-visible spectrophotometer. Chlorophyll (Chl) a, b and carotenoid (Car) contents were calculated following the procedure described by Lichtenthaler and Wellburn (1983).

\subsection{Statistical analysis}

Analysis of variance (ANOVA) was conducted using the SAS Statistical Analysis System (SAS version 9.3; SAS Institute Inc., Cary, NC). Each value was presented as the mean \pm standard deviation $(\mathrm{SD})$, with a minimum of five replicates. Differences between treatment means were tested by the Least Significant Difference (LSD) method at $\alpha=0.05$ level of significance. Figures were plotted using Origin 7.0 software (Origin Lab, Northampton, MA, USA).

\section{Results}




\subsection{ANOVA on the effects of Salt, Sulfur, and their interaction}

The experiment affected all response variables (Table 1.) There were significant main effects for the Salt treatment on all variables except $P_{n}$ and qN. There were also significant main effects for the Sulfur treatment on all variables except $C i$ (Table 1). Except DW, Total Chl, and Car contents, all other variables were significantly different, showing the great impacts from Salt and Sulfur interaction.

\subsection{Leaf mass and size}

To determine leaf mass changes, leaf fresh and dry weights per unit area (FW and DW) of the excessive sulfur fumigation stress and salt pre-treated plants were compared to plants in the CK treatment. The Sulfur treatment significantly decreased FW and DW by $39.4 \%$ and $10.1 \%$, respectively (Fig.1). While the Salt treatment increased them by $13.7 \%$ and $16.2 \%$, respectively. The Salt+Sulfur treatment showed no significant difference in FW and DW when compared to the CK treatment.

The Salt treatment clearly decreased the tomato leaf size compared to the CK treatment (Fig. 2). Leaf size in the Sulfur treatment decreased more than in the Salt treatment, and the edge of leaves showed serious dryness and shrinkage. The Salt+Sulfur treatment only exhibited some dry spots on the leaves.

\subsection{Leaf Chl and Car contents}

Total Chl and Car contents exhibited similar changes in response to sulfur fumigation treatment (Fig. 3). The Salt treatment significantly enhanced Chl and Car 
221

222

by $21.2 \%$ and $24.3 \%$, respectively. The Sulfur treatments significantly decreased Chl and Car by $38.4 \%$ and $48.5 \%$, respectively (Fig. 3). The Salt+Sulfur treatments decreased Chl and Car by only $16.4 \%$ and $19.1 \%$, respectively. Compared to the Sulfur treatment, the Salt+Sulfur treatment significantly enhanced total Chl and Car contents. There were no significant differences between the Salt and CK in the ratios of $\mathrm{Chl} \mathrm{a/} \mathrm{b} \mathrm{and} \mathrm{Car/} \mathrm{total} \mathrm{Chl.} \mathrm{Sulfur} \mathrm{treatment} \mathrm{significantly} \mathrm{decreased} \mathrm{Chl} \mathrm{a} / \mathrm{b}$ and Car/ total Chl, but the Salt+Sulfur treatment only slightly decreased these two variables compared to the CK (Fig. 3).

\subsection{Leaf photosynthesis}

The Sulfur and Salt treatment significantly influenced leaf photosynthesis and transpiration (Fig. 4). $P_{n}, G_{s}$, and $T_{r}$ were significantly decreased by the Salt, Sulfur, and Salt+Sulfur treatments, compared to the CK. Sulfur caused the largest reductions (97.2\%, 96.4\% and 94.8\%, respectively), followed by the Salt+Sulfur treatment (65.9\%, 88.6\% and $84.3 \%$, respectively). The Salt treatment led to the smallest reductions $(23.0 \%, 70.8 \%$ and $62.4 \%$, respectively). The Salt and Salt+Sulfur treatments also significantly reduced $C_{i}(28.8 \%$ and $33.3 \%$, respectively) and the Sulfur only treatment significantly improved $C_{i}(122.1 \%)$.

\subsection{Leaf chlorophyll fluorescence}

To further determine the effects of pre-treatment with salt on the responses of tomato plants to excessive sulfur fumigation, chlorophyll fluorescence parameters were measured. The $\Phi_{\mathrm{PSII}}, \mathrm{ETR}, \mathrm{qP}, \mathrm{Fv}^{\prime} / \mathrm{Fm}^{\prime}, \mathrm{qN}$ and Fv/Fm of plants in the Salt treatment were not significantly different from the CK. But the Sulfur only treatment 
reduced $\Phi_{\mathrm{PSII}}$, ETR, $\mathrm{qP}, \mathrm{Fv}^{\prime} / \mathrm{Fm}^{\prime}$ and $\mathrm{Fv} / \mathrm{Fm}$ by $74.4 \%, 74.4 \%, 46.8 \%, 56.1 \%$, and 34.6\%, respectively (Fig. 5). The Salt+Sulfur treatment significantly increased these above-described parameters by $2.80,2.79,1.62,1.85$, and 1.45 times, respectively, compare to the Sulfur treatment. Both the Sulfur and Salt+Sulfur treatments significantly enhanced $\mathrm{qN}$ but the Sulfur treatment increased $\mathrm{qN}$ at a greater magnitude than the Salt+Sulfur treatment.

The severe damage of Sulfur treatment was clear visible 0d, 1d, 2d, 5d, and 8d after the stress (Fig. 6). Plant leave wilted and started to dry 2 days after Sulfur stress, but plants in the Salt+Sulfur treatment showed better tolerance than plants in the Sulfur treatment. New leave started to grow for both treatments 8 days after the sulfur fumigation.

\section{Discussion}

By exposing tomato plants to excessive sulfur fumigation stress, we demonstrated that a cross-tolerance occurred with salt pre-treated plants. While the Sulfur treatment significantly damaged leaf photosynthetic system and chlorophyll fluorescence system, plants pre-treated with salt showed much improved performance which supported our hypotheses. Two potential mechanisms could account for this cross-tolerance. 1) By maintaining high leaf mass per unit area, plus high chlorophyll and carotenoid contents under salt stress, plants could protect their leaves from excessive sulfur fumigation damage by promoting leave metabolite accumulation. Leaf weight, Chl, and Car were significantly enhanced in the 
Salt+Sulfur treatment compared to the Sulfur only treatment in this study. These changes improved tomato plants tolerance to excessive sulfur fumigation stress. 2) Enhancement of the activity of leaf PSII reaction center, electron transport, the light harvesting complexes and proper thermal dissipation under the Salt+Sulfur treatment helped maintain the leaf photosynthetic performance under the excessive sulfur fumigation stress. Indeed, photosynthesis, $\Phi_{\mathrm{PSII}}, \mathrm{ETR}, \mathrm{qP}, \mathrm{Fv}^{\prime} / \mathrm{Fm}^{\prime}$ and $\mathrm{Fv} / \mathrm{Fm}$ all were significantly enhanced in the Salt and Salt+Sulfur treatments. The findings revealed here improve our understanding of salt and sulfur stress responses and could be useful for reducing the effect of excessive sulfur exposure to crops.

Salt stress significantly increased the leaf fresh and dry weight per unit area (Fig. 1), however, plants pre-treated with salt seemed to reduce leaf surface expansion (Fig.2). This was consistent with a previous study showing that salt stress reduces the rate of leaf surface expansion and eventually stops the expansion as salt concentration increases (Wang and Nil, 2000). Zhu et al. (2001) found that plants subjected to salt stress produce more stress proteins and compatible osmolytes. Proline level is mostly increased when plants suffered salinity stress (Parida and Das, 2005; Silveira, et al., 2003; 2012). Mohamed et al. (2007) also confirmed that significantly more proline was accumulated in the six different tomato varieties under $100 \mathrm{mM} \mathrm{NaCI}$ treatment compared to the controls. Claussen (2005) concluded that proline is a reliable indicator of the environmental stress imposed on tomato plants. In this study, the Salt+Sulfur treatment accumulated more carbohydrates per unit area which may be translated into higher productivity under the Sulfur stress, 
and thus protecting leaves from excessive sulfur injury.

It is well known that $\mathrm{Chl}$ and $\mathrm{Car}$ are essential components of the plant photosynthetic apparatus. Their roles in light harvesting, stabilization of thylakoid membranes, and energy transduction are well established (Tanaka and Tanaka, 2006; Havaux, 1998). In this study we found that the Salt treatment significantly enhanced total Chl and Car contents, but the Sulfur treatment had an opposite effect. It has been established that an increase in chlorophyll content under salt stress could be used as a biochemical indicator for salt tolerance (Stefanov et al., 2016). Our result was in agreement with previous studies that Car could serve as a photo-protection agent by quenching singlet oxygen which might otherwise damage chlorophyll (Qin et al., 2007). Therefore, moderate salt stress enhanced the plant production of Chl and Car in order to maintain a properly functioning photosynthetic system. Saito et al. (2008) also found that moderate salinity stress in tomato during the fruit developmental stage could promote metabolite accumulation and increase fruit firmness, resulting in an improvement in fruit quality. However, severe sulfur fumigation stress damaged the leaf structure, leading to a decline in $\mathrm{Chl}, \mathrm{Chl}$ a/b and $\mathrm{Car}, \mathrm{Car} / \mathrm{Chl}$ contents. The increase in $\mathrm{Chl} \mathrm{a} / \mathrm{b}$ ratio is linked to plant resistance (Misra et al., 1997; Shahbaz et al., 2008). Here the observed decreases in Chl a/b and Car /Chl in the Sulfur treatment indicated that plants had suffered serious damage during the treatment period.

Photosynthesis is the fundamental physiological process which provides energy and assimilates for growth and reproduction in plants (Lawlor, 2009). Photosynthesis 
is also a sensitive biological process much influenced by stresses (Ashraf and Harris, 2013). To protect the photosynthetic systems from injury, plants often increase energy dissipation in PSII (Yuan et al., 2014). In this study, we found that $P_{n}, G_{s}$, and $T_{r}$ were significantly decreased in the Salt, Sulfur, and Salt+Sulfur treatments. Leaf photosynthesis declined to near zero in the Sulfur treatment which suggests that those tomato leaves were almost completely damaged (Figs. 2,4,6). Pre-treating plant leaves significantly relieved the injury, and resulted in much higher levels of photosynthesis. In the Salt and Salt+Sulfur treatments, the reductions of $P_{n}, G_{s}$ and $T_{r}$ were accompanied with a drop of $C_{i}$, indicating a stomatal limitation on photosynthesis. But in the Sulfur treatment, $C_{i}$ was significant increased as $P_{n}, G_{s}$ and $T_{r}$ were clearly decreased, indicating that other non-stomatal limitation might be a main cause of a reduction in photosynthesis (Zhou et al., 2007).

The use of chlorophyll fluorescence as a rapid non-destructive method to examine photosynthetic performance and stress in plants is now widespread in physiological and ecophysiological studies (Baker, 2008; Calatayud et al., 2006; Osório et al., 2013). $\Phi_{\text {PSII }}$ is a measure of the quantum efficiency of photochemical energy dissipation which relates to the utilization of photons absorbed by the PSII antennae, and $\mathrm{qP}$ measures the proportion of PSII reaction centers capable of photochemistry (Baker and Rosenqvist, 2004; Ding et al., 2016). ETR is an estimate of the number of electrons transported through PSII under steady state photosynthetic conditions which has also been shown to correlate well with gas exchange photosynthesis measurements under many types of plant stress conditions (Krall and 
Edwards, 1992). $\mathrm{F}_{\mathrm{v}}{ }^{\prime} / \mathrm{F}_{\mathrm{m}}$ ' estimates the maximum efficiency of PSII photochemistry at a given light intensity, which is the PSII operating most efficiently when all the PSII centers are open. $F_{v} / F_{m}$ is the maximum efficiency at which light absorbed by PSII is used for reduction of $\mathrm{Q}_{\mathrm{A}}$ (the primary quinone electron acceptor of PSII) which has been widely used to detect stress-induced perturbations in the photosynthetic apparatus (Butler, 1978; Baker and Rosenqvist, 2004). Non-photochemical quenching (qN) processes quench singlet-excited chlorophylls and harmlessly dissipate excessive excitation energy as heat, thus helping to regulate and protect photosynthesis in response to excess light energy (Müller et al., 2001). Our results showed that there were no significant changes between the Salt treatment and CK for all of the chlorophyll fluorescence parameters indicate that the moderate Salt treatment did not change plant photosynthetic systems much, especially the PSII reaction centers. Similar results were reported for salinity tolerance in rice (Dionisio-Sese and Tobita, 2000). The Sulfur treatment significantly decreased $\Phi_{\mathrm{PSII}}, \mathrm{ETR}, \mathrm{qP}, \mathrm{F}_{\mathrm{v}}{ }^{\prime} / \mathrm{F}_{\mathrm{m}}{ }^{\prime}, \mathrm{F}_{\mathrm{v}} / \mathrm{F}_{\mathrm{m}}$ and increased $\mathrm{qN}$ which suggests that the PSII reaction center and the light harvesting complexes suffered seriously that the photoinhibition was activated (Laisk et al., 2014), and that plants enhanced thermal dissipation to protect leaves from serious damage due to excessive energy excitation in the reaction centers (Salvucci et al., 2001; Yuan et al., 2014). Our results also revealed that the Salt+Sulfur treatment significantly relieved excessive sulfur damage of the leave, increased $\Phi_{\text {PSII, }}$ ETR, qP, $\mathrm{F}_{\mathrm{v}} / \mathrm{F}_{\mathrm{m}}{ }^{\prime}$, and $\mathrm{F}_{\mathrm{v}} / \mathrm{F}_{\mathrm{m}}$, and decreased $\mathrm{qN}$ compared to the Sulfur treatment. 


\section{Conclusion}

354

Tomato plants pre-treated with salt in the soil clearly strengthened the plant tolerance to excessive sulfur fumigation stress. We found that 1) the Salt treatment significantly reduced plant growth, but enhanced leaf weight per area and total chlorophyll and carotenoid contents. The Sulfur only treatment severely damaged tomato leave, their photosynthetic system and chlorophyll fluorescence system; and 2) plants in the Salt+Sulfur treatment were able to maintain higher leaf mass per area, total chlorophyll and carotenoid contents, and photosynthetic activities. Our results supported our hypothesis that a cross-tolerance exists between the salt stress and extreme sulfur fumigation stress. Such a cross-tolerance might be further exploited to improve plants tolerances under other stresses (such as sudden cold, heat, and flooding). Future research should be conducted to elucidate these physiobiochemical processes at the cellular and molecular levels to improve our understanding of plant cross-tolerance to stresses.

\section{Acknowledgments}

This work was supported by the USDA National Institute of Food and Agriculture, Evans-Allen project (TENX1622-CC), and USDA CBG project (2013-38821-21390). $\mathrm{XD}$ and YJ are grateful to the National Key Technology Support Program of China (2014BAD08B01). The funders had no role in study design, data collection and analysis, decision to publish, or preparation of the manuscript. We also thank Dr. Phil Ganter for the technical editing of the manuscript. 
376 Author Contributions: Conceived and designed the experiments: DH. Performed

377 the experiments: YJ, XD. Analyzed the data: YJ, XD. Contributed 378 reagents/materials/analysis tools: SZ, QD, ZY, DZ. Critical revision of the paper: 379 YJ, DZ. Wrote the paper: YJ, XD, DH.

\section{Reference}

Aroca, R., Irigoyen, J.J., Sanchez-Diaz, M., 2003. Drought enhances maize chilling tolerance. II. Photosynthetic traits and protective mechanisms against oxidative stress. Physiol. Plantarum. 117, 540-549.

Ashraf, M., Harris, P., 2013. Photosynthesis under stressful environments: an overview. Photosynthetica 51, 163-190.

Astolfi, S., Zuchi, S., 2013. Adequate S supply protects barley plants from adverse effects of salinity stress by increasing thiol contents. Acta Physiol. Plant. 35, 175-181.

Astolfi, S., Zuchi, S., Neumann, G., Cesco, S., di Toppi, L., Pinton, R., 2012. Response of barley plants to Fe deficiency and Cd contamination as affected by S starvation. J. Exp. Bot. 633, 1241-1250.

Baker, N.R., 2008. Chlorophyll fluorescence: a probe of photosynthesis in vivo. Annu. Rev. Plant Biol. 59, 89-113.

Baker, N.R., Rosenqvist, E., 2004. Applications of chlorophyll fluorescence can improve crop productions strategies: an examination of future possibilities. J. 
Butler, W.L., 1978. Energy distribution in the photochemical apparatus of photosynthesis. Annu. Rev. Plant Physiol. 29, 345-378.

400

401

402

403

404

405

406

407

408

409

410

411

412

413

414

415

416

417

418

Calatayud, A., Roca, D., Martínez, P.F., 2006. Spatial-temporal variations in rose leaves under water stress conditions studied by chlorophyll fluorescence imaging. Plant Physiol. Biochem. 44, 564-573.

Capiati, D.A., País, S.M., Téllez-Iñón, M.T., 2006. Wounding increases salt tolerance in tomato plants: evidence on the participation of calmodulin-like activities in cross-tolerance signalling. J. Exp. Bot. 57, 2391-2400.

Carkirlar, H., Cicek, N., Fedina, I., Georgieva, K., Dogru, A., Velitchkova, M., 2008. $\mathrm{NaCl}$ induced cross-acclimation to UV-B radiation in four barley (Hordeum vulgare L.) cultivars. Acta Physiol. Plant. 30, 561-567.

Celletti, S., Paolacci, A.R., Mimmo, T., Pii, Y., Cesco, S., Ciaffi M., Astolfi S., 2016. The effect of excess sulfate supply on iron accumulation in three graminaceous plants at the early vegetative phase. Environ. Exp. Bot. 128, 31-38.

Cerkauskas, R.F., Brown, J., 2015. Aspects of the epidemiology and control of powdery mildew (Oidium neolycopersici) on tomato in Ontario, Canada. Can. J. Plant Pathol. 37, 448-464.

Cerkauskas, R.F., Ferguson, G., 2014. Management of powdery mildew (Podosphaera xanthii) on greenhouse cucumber in Ontario. Can. J. Plant Pathol. $36,22-37$.

Clausen, W., 2005. Proline as a measure of stress in tomato plants. Plant Sci. 168, 
Ding, X.T., Jiang, Y.P., Hao, T., Jin, H.J., Zhang, H.M., He, L.Z., Zhou, Q., Huang, D.F., Hui, D.F., Yu, J.Z., 2016. Effects of heat shock on photosynthetic properties, antioxidant enzyme activity, and Downy mildew of cucumber $\begin{array}{llllll}\text { (Cucumis sativus } & \text { L.). } & \text { PLoS } & \text { ONE } & \text { 11(4): } & \text { e0152429. }\end{array}$ doi:10.1371/journal.pone.0152429.

Dionisio-Sese, M., Tobita, S., 2000. Effect of salinity on sodium content and photosynthetic responses of rice seedlings differing in salt tolerance. J. Plant Physiol. 157, 54-58.

Dodd, I.C., Doley, D., 1998. Growth responses of cucumber seedlings to sulphur dioxide fumigation in a tropical environment. Environ. Exp. Bot. 39, 41-47.

Havaux, M., 1998. Carotenoids as stabilisers in chloroplasts. Trends Plant Sci. 3, $147-151$.

Hossain, M.A., Mostofa, M.G., Fujita, M., 2013. Heat-shock positively modulates oxidative protection of salt and drought-stressed mustard (Brassica campestris L.) seedlings. J. Plant Sci. Mol. Breed. 2, 1-14.

Jiang, X., Huang, L.F., Zheng, S.H., Chen, S.L., 2013. Sulfur fumigation, a better or worse choice in preservation of Traditional Chinese Medicine? Phyto Medicine 20, 97-105.

Kitajima, M., Butler, W., 1975. Quenching of chlorophyll fluorescence and primary photochemistry in chloroplasts by dibromothymoquinone. Biochim. Biophys. Acta 376, 105-115. 
Krall, J.P., Edwards, G.E., 1992. Relationship between photosystem II activity and $\mathrm{CO}_{2}$ fixation in leaves. Physiol. Plant. 86, 180-187.

Laisk, A., Oja, V., Eichelmann, H., Dall'Osto L., 2014. Action spectra of photosystems II and I and quantum yield of photosynthesis in leaves in State 1. BBA-Bioenergetics 1837, 315-325.

Lawlor, D.W., 2009. Musings about the effects of environment on photosynthesis. Ann. Bot. 103, 543-549.

Lee, B.R., Zaman, R., Avice, J.C., Ourry, A., Kim, T.H., 2016. Sulfur use efficiency is a significant determinant of drought stress tolerance in relation to photosynthetic activity in Brassica napus cultivars. Front. Plant Sci. 7:459. doi: 10.3389/fpls.2016.00459.

Lewandowska, M., Sirko, A., 2008. Recent advances in understanding plant response to sulfur-deficiency stress. Acta Biochim. Pol. 55, 457-471.

Lichtenthaler, H.K., Wellburn, A.R., 1983. Determinations of total carotenoids and chlorophylls a and b of leaf extracts in different solvents. Biochem. Soc. Trans. 11, 591-592.

Lu, C.M., Qiu, N.W., Wang, B.S., Zhang, J.H., 2003. Salinity treatment shows no effects on photosystem II photochemistry, but increases the resistance of photosystem II to heat stress in halophyte Suaeda salsa. J. Exp. Bot. 54, $851-860$.

Ma, N.N., Zuo, Y.Q., Liang, X.Q., Yin, B., Wang, G.D., Meng, Q.W., 2013. The multiple stress-responsive transcription factor SINAC1 improves the chilling 
464

Misra, A., Sahu, S., Misra, M., Singh, P., Meera, I., Das, N., Kar, M., Sahu, P., 1997. Sodium chloride induced changes in leaf growth, and pigment and protein contents in two rice cultivars. Biol. Plant 39, 257-262.

Mohamed A.N., Rahman M.H., Alsadon A.A., Islam R., 2007. Accumulation of proline in NaCl-treated callus of six tomato (Lycopersicon esculentum Mill.) cultivars, Plant Tissue Cult. Biotech. 17, 217-220.

Munns, R., Tester, M., 2008. Mechanisms of salinity tolerance. Annu. Rev. Plant Biol. 59, 651-681.

Müller, P., Li, X.P., Niyogi, K.K., 2001. Non-photochemical quenching. A response to excess light energy. Plant Physiol.125, 1558-1566.

Osório, M.L., Osório, J., Romano, A., 2013. Photosynthesis, energy partitioning, and metabolic adjustments of the endangered Cistaceae species Tuberaris major under high temperature and drought. Photosynthetica 51, 75-84.

Parida, A.K., Das, A.B., 2005. Salt tolerance and salinity effects on plants: a review. Ecotox. Environ. Safe. 60, 324-349.

Puniran-Hartley, N., Hartley, J., Shabala, L., Shabala, S., 2014. Salinity-induced accumulation of organic osmolytes in barley and wheat leaves correlates with increased oxidative stress tolerance: in planta evidence for cross-tolerance. Plant Physiol. Biochem. 83, 32-39.

Qin, G., Gu, H., Ma, L., Peng, Y., Deng, X.W., Chen, Z., Qu, L.J., 2007. Disruption of phytoene desaturase gene results in albino and dwarf phenotypes in 
Arabidopsis by impairing chlorophyll, carotenoid, and gibberellin biosynthesis. Cell Res. 17, 471-482.

487

Rao, K.J., Paria, S., 2013. Use of sulfur nanoparticles as a green pesticide on Fusarium solani and Venturia inaequalis phytopathogens. RSC Adv. 3, 10471-10478.

Rohacek, K., 2002. Chlorophyll fluorescence parameters: the definitions, photosynthetic meaning and mutual relationships. Photosynthetica 40, 13-29.

Salvucci, M.E., Osteryoung, K.W., Crafts-Brandner, S.J., Vierling, E., 2001. Exceptional sensitivity of rubisco activase to thermal denaturation in vitro and in vivo. Plant Physiol. 127, 1053-1064.

Saito, T., Matsukura, C., Ban, Y., Shoji, K., Sugiyama, M., Fukuda, N., Nishimura, S., 2008. Salinity stress affects assimilate metabolism at the gene-expression level during fruit development and improves fruit quality in tomato (Solanum lycopesicum L.). J. Japan. Soc. Hort. Sci. 77, 61-68.

Serna, M., Coll, Y., Zapata, P.J., Botella, M.Á., Pretel, M.T., Amorós, A., 2015. A brassinosteroid analogue prevented the effect of salt stress on ethylene synthesis and polyamines in lettuce plants. Sci. Hortic-Amsterdam 185, 105-112.

Shahbaz, M., Ashraf, M., Athar, H., 2008. Does exogenous application of 24-epibrassinolide ameliorate salt induced growth inhibition in wheat (Triticum aestivum L.)? Plant Growth Regul. 55, 51-64.

Silveira, J.A.G., Júnior, J.M., Silva, E.N., Ferreira-Silva, S.L., Aragão, R.M., Viégas, R.A., 2012. Salt resistance in two cashew species is associated with 
accumulation of organic and inorganic solutes. Acta Physiol. Plant. 34, 1629-1637.

Silveira, J.A.G., Viégas, R.D.A., da Rocha, I.M.A., Moreira, A.C.O.M., Moreira, R.D.A., Oliveira, J.T.A., 2003. Proline accumulation and glutamine synthetase activity are increased by salt-induced proteolysis in cashew leaves. J. Plant Physiol. 160:115-123.

Stefanov, M., Yotsova, E., Rashkov, G., Ivanova, K., Markovska, Y., Apostolova, E.L., 2016. Effects of salinity on the photosynthetic apparatus of two Paulownia lines. Plant Physiol. Bioch. 101, 54-59.

Tanaka, A., Tanaka, R., 2006. Chlorophyll metabolism. Curr. Opin. Plant Biol. 9, 248-255.

Türkan, I., Demiral, T., 2009. Recent developments in understanding salinity tolerance. Environ. Exp. Bot. 67, 2-9.

USEPA, 1991. Sulfur Reregistration Eligibility Decision (RED) Fact Sheet. http://www.epa.gov/oppsrrd1/REDs/factsheets/0031fact.pdf.

Wang, Y., Cai, S.Y., Yin, L.L., Shi, K., Xia, X.J., Zhou, Y.H., Yu, J.Q., Zhou, J., 2015. Tomato HsfA1a plays a critical role in plant drought tolerance by activating ATG genes and inducing autophagy, Autophagy, 11, 2033-2047.

Wang, Y., Nil, N., 2000. Changes in chlorophyll, ribulose biphosphate carboxylase-oxygenase, glycine betaine content, photosynthesis and transpiration in Amaranthus tricolor leaves during salt stress. J. Hortic. Sci. Biotechnol. 75, 623-627. 
Wright, P.J., Gardner-Gee, R., Walker, G.P., Hedderley, D.I., 2015. Effect of sulphur foliar applications on the tomato-potato psyllid (Bactericera cockerelli) in a potato crop. New Zeal. J. Crop Hort. 43, 59-67.

Yi, C.Y., Yao, K.Q., Cai, S.Y., Li, H.Z., Zhou, J., Xia, X.J., Shi, K., Yu, J.Q., Foyer C.H., Zhou, Y.H., 2015. High atmospheric carbon dioxide-dependent alleviation of salt stress is linked to RESPIRATORY BURST OXIDASE 1 (RBOH1)-dependent $\mathrm{H}_{2} \mathrm{O}_{2}$ production in tomato (Solanum lycopersicum) J. Exp. Bot. 66, 7391-7404.

Yuan, Y.H., Shu, S., Li, S.H., He, L.Z., Li, H., Du, N.S., Sun, J., Guo, S.R., 2014. Effects of exogenous putrescine on chlorophyll fluorescence imaging and heat dissipation capacity in cucumber (Cucumis sativus L.) under salt stress. J. Plant Growth Regul. 33, 798-808.

Zhu, J.K., 2001. Plant salt tolerance. Trends plant sci. 6, 66-71.

Zhou, J., Xia, X.J., Zhou, Y.H., Shi, K., Chen, Z.X., Yu, J.Q., 2014. RBOH1-dependent $\mathrm{H}_{2} \mathrm{O}_{2}$ production and subsequent activation of MPK1/2 play an important role in acclimation-induced cross-tolerance in tomato. J. Exp. Bot. 65, 595-607.

Zhou, Y.H., Lam, H.M., Zhang, J.H., 2007. Inhibition of photosynthesis and energy dissipation induced by water and high light stresses in rice. J. Exp. Bot. 58, 1207-1217. 
Table1. ANOVA of the effects of pre-treated with salt (Salt), excessive sulfur fumigation (Sulfur) and their interaction on physiological variables one day after the excessive sulfur treatment. Numbers are F values. FW, fresh weight per unit area; DW, dry weight per unit area; Chl, chlorophyll; Car, carotenoid; $P_{n}$, net photosynthetic rate; $G_{s}$, stomatal conductance; $C_{i}$, intercellular $\mathrm{CO}_{2}$ concentration; $T_{r}$, transpiration; $\Phi_{\mathrm{PSII}}$, actual photochemical efficiency of PSII; ETR, electron transport rate; qP, photochemical quenching coefficient; Fv'/Fm', effective quantum yield of PSII photochemistry; Fv/Fm, maximum quantum efficiency of PSII photochemistry; qN, non-photochemical quenching coefficients. *: significant at $\alpha=0.05 ; * *$ : significant at $\alpha=0.01$.

\begin{tabular}{|c|c|c|c|c|c|c|c|c|}
\hline Treatment & $\mathrm{FW}$ & DW & Total Chl & Car & Chl a/b & $\begin{array}{l}\text { Car/ Total } \\
\text { Chl }\end{array}$ & $P_{n}$ & $G_{s}$ \\
\hline Salt & $203.20^{* *}$ & $67.70^{* *}$ & $97.74^{* *}$ & $270.62^{* *}$ & $8.51^{* *}$ & $12.54^{* *}$ & 0.20 & $90.34^{* *}$ \\
\hline Sulfur & $214.58^{* *}$ & $37.83^{* *}$ & $302.01^{* *}$ & $792.57^{* *}$ & $44.49^{* *}$ & $25.99^{* *}$ & $890.58^{* *}$ & $302.61^{* *}$ \\
\hline Salt* Sulfur & $65.20^{* *}$ & 0.72 & 0.03 & 2.44 & $9.79^{* *}$ & $5.63^{*}$ & $125.12^{* *}$ & $128.53^{* *}$ \\
\hline Treatment & $C i$ & $T_{r}$ & $\Phi_{\mathrm{PSII}}$ & ETR & $\mathrm{qP}$ & $\mathrm{Fv}^{\prime} / \mathrm{Fm}^{\prime}$ & $\mathrm{Fv} / \mathrm{Fm}$ & $\mathrm{qN}$ \\
\hline Salt & $50.33^{* *}$ & $91.48^{* *}$ & $43.38^{* *}$ & $42.77^{* *}$ & $15.94^{* *}$ & $22.05^{* *}$ & $12.99^{* *}$ & 1.98 \\
\hline Sulfur & 2.66 & $450.08^{* *}$ & $257.37^{* *}$ & $257.38^{* *}$ & $45.24^{* *}$ & $95.67^{* *}$ & $24.37^{* *}$ & $68.10^{* *}$ \\
\hline Salt* Sulfur & $5.49^{*}$ & $159.34^{* *}$ & $39.27^{* *}$ & $39.23^{* *}$ & $10.14^{* *}$ & $29.61^{* *}$ & $14.02^{* *}$ & $9.02^{* *}$ \\
\hline
\end{tabular}




\section{Figure Captions}

Fig. 1. Effects of excessive sulfur fumigation stress on leaf fresh weight (FW) and dry weight (DW) per unit area of different treatments one day after the excessive sulfur fumigation treatment. Data represent mean \pm SE $(n=5)$. Different letters indicate significant differences at $\alpha=0.05$ based on the Least Significant Difference test. CK: plants grown in glasshouse one, with no salt pre-treatment and no excessive sulfur fumigation stress applied; Salt: plants grown in glasshouse one, pre-treated with 100 $\mathrm{mM}$ of $\mathrm{NaCl}$ and no excessive sulfur fumigation stress applied; Sulfur: plants grown in glasshouse two, not pre-treated with salt, but fumigated with excessive sulfur; Salt+Sulfur: plants grown in glasshouse two, both pre-treated with $100 \mathrm{mM}$ of $\mathrm{NaCl}$ and fumigated with excessive sulfur.

Fig. 2. Leaf pictures of different treatments to the responses of excessive sulfur fumigation stress of cucumber seedlings 1 day after the excessive sulfur stress fumigation treatment.

Fig. 3. Effects of excessive sulfur fumigation stress on total chlorophyll content, carotenoid content, chlorophyll $\mathrm{a} / \mathrm{b}$, and carotenoid/total chlorophyll of different treatments 1 day after the excessive sulfur treatment. Data represent the mean $\pm \mathrm{SE}$ (n $=5$ ). Different letters indicate significant differences at $\alpha=0.05$ based on the Least Significant Difference test.

Fig. 4. Effects of excessive sulfur fumigation stress on net photosynthetic rate $\left(P_{n}\right)$, stomatal conductance $\left(G_{s}\right)$, intercellular $\mathrm{CO}_{2}$ concentration $\left(C_{i}\right)$ and transpiration rate 
$\left(T_{r}\right)$ of different treatments 1 day after the excessive sulfur fumigation treatment. Data represent the mean $\pm S E(n=5)$. Different letters indicate significant differences at $\alpha=0.05$ based on the Least Significant Difference test.

Fig. 5. Effects of excessive sulfur fumigation stress on actual photochemical efficiency of PSII ( $\left.\Phi_{\mathrm{PSII}}\right)$, photochemical quenching coefficient $(\mathrm{qP})$, Electron transport rate (ETR), and the effective quantum yield of PSII photochemistry $\left(\mathrm{F}_{\mathrm{v}}{ }^{\prime} / \mathrm{F}_{\mathrm{m}}{ }^{\prime}\right)$, maximum quantum efficiency of photosystem II (PSII) photochemistry $\left(\mathrm{F}_{\mathrm{v}} / \mathrm{F}_{\mathrm{m}}\right)$ and non-photochemical quenching coefficients (qN)of different treatments 1 day after the excessive sulfur treatment. Data represent the mean \pm SE $(n=5)$. Different letters indicate significant differences at $\alpha=0.05$ based on the Least Significant Difference test.

Fig. 6. Pictures of plant changes in the Sulfur and Salt+Sulfur treatments after 0, 1, 2, 5, 8 days of excessive sulfur fumigation stress. 


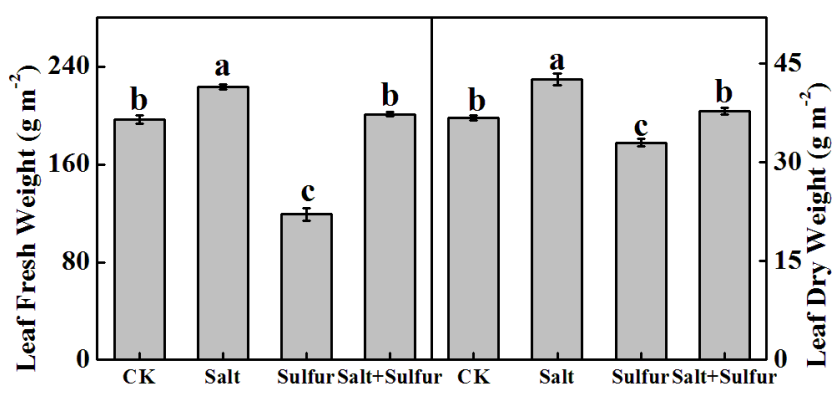




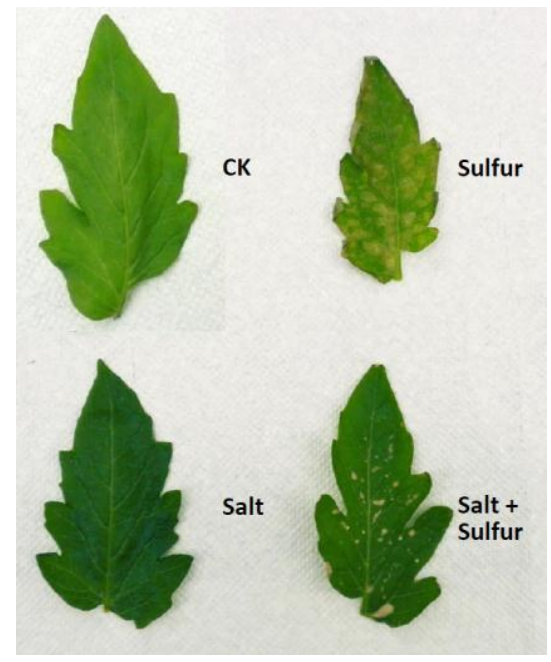




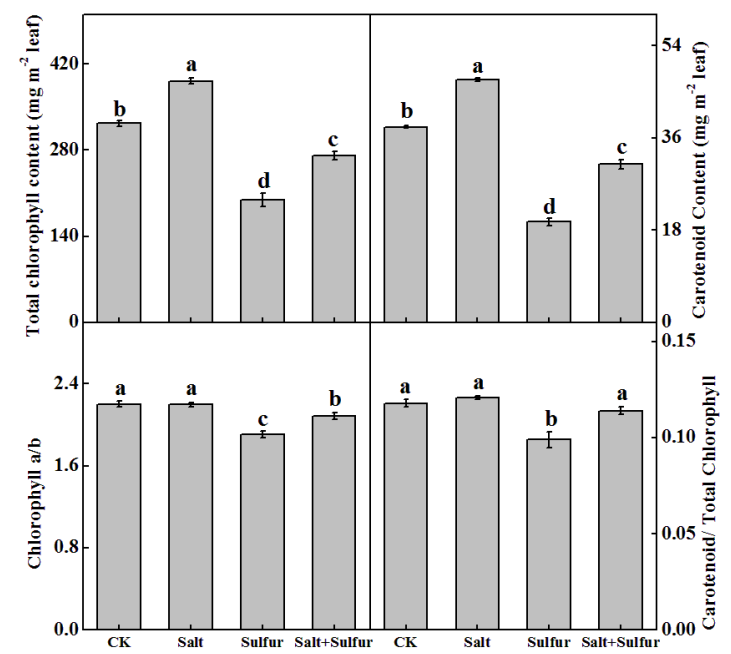




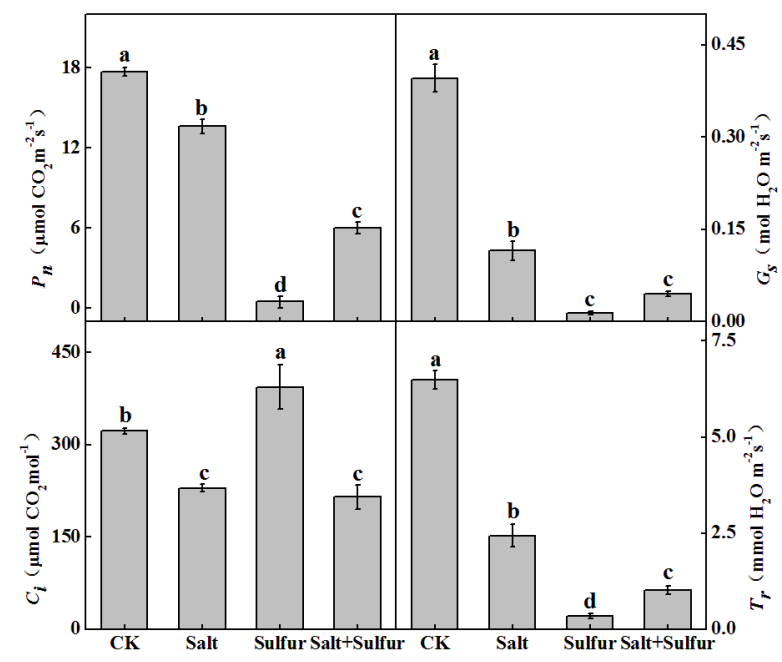




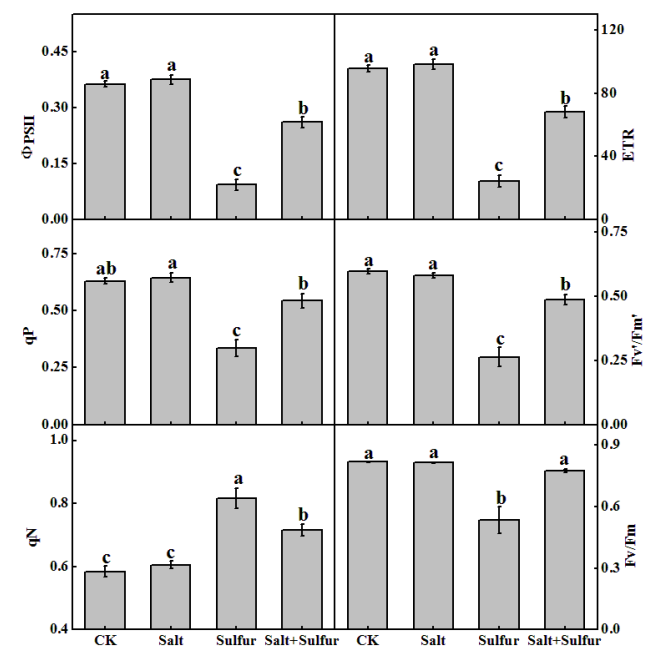


Sulfur Salt +Sulfur

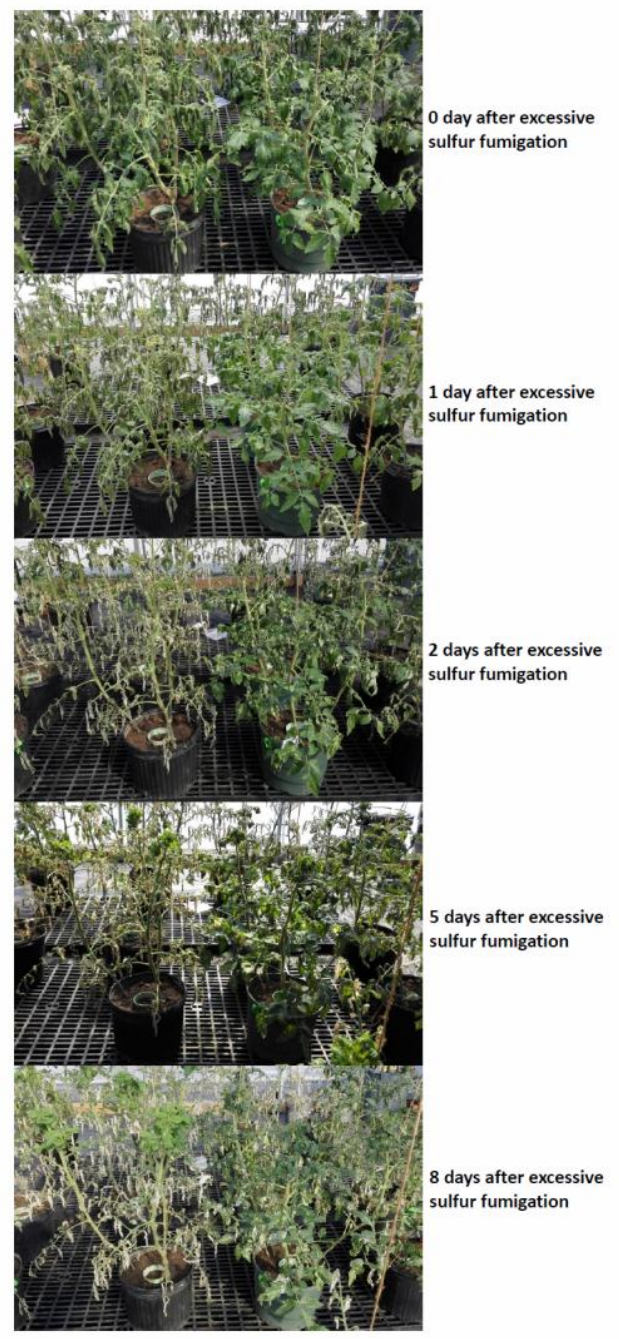

